\title{
Venture funding for new ideas
}

\section{Explanations for anomalies should be sought with an open mind.}

\section{W}

Jayant V. Narlikar or centuries, kings in India had a tradition of rewarding excellence in all creative fields, such as literature, music, fine arts and craftsmanship. The needy scholar had only to approach the royal court, demonstrate his creativity and be assured of financial support. However, from the seventeenth century onwards, as science began to make its presence felt in Europe, the Indian potentates did not appreciate its potential. The lack of royal patronage is one of the many suggested causes of the underdevelopment of science in India. This royal apathy came at a heavy price, as one of the reasons for the colonial dominance of India was the lack of growth of science and technology in the country.

In Europe, there were patrons for science among the royalty and rich aristocracy. Some scientists, such as Edmund Halley, Henry Cavendish or Charles Darwin, were well-to-do and could support their own research. But this trend of the eighteenth and nineteenth centuries began to change in the twentieth century, as scientific research became more and more expensive. Ernest Rutherford's pioneering experiments on the atomic nucleus were performed with apparatus costing around $£ 100$. Modern highenergy accelerators cost billions of dollars, for in order to delve deeper into the ultimate structure of particles, probes of higher and higher energy are required. At the other end of the size spectrum, astronomers need more and more expensive infrastructure to observe the Universe to fainter and farther limits. It is a far cry from Galileo's one-inch telescope of 1609 , designed by himself, to the Keck Telescope of 10 metres' aperture nearly four centuries later.

Once such expensive facilities are created, often using the resources of several nations, it becomes essential to make the most efficient use of them. So applications to use the equipment are invited and judged by a peer-review process. The reviewers are conscious of the fact that the proposed experiment should

\section{he extreme \\ caution exercised by reviewers allows only the very safe proposals to get through.}

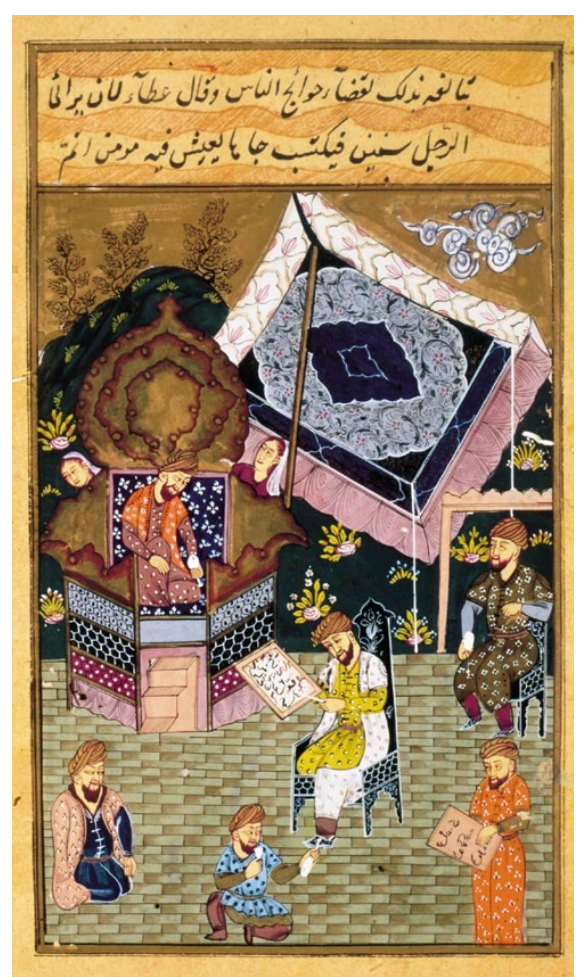

A king's ransom? Royal patronage is no longer a reliable source of scientific funding.

advance the frontiers of knowledge, but at the same time it should be one for which the facility is essential. Thus proposals that are not scientifically well motivated or which can be carried out using other less sophisticated facilities are turned down.

All this looks reasonable. Yet the extreme caution that must be exercised by the reviewers allows only the very 'safe' proposals to get through. Here, safety is judged through the prevailing paradigm. What is expected under the existing paradigm? Does the proposal advance the existing knowledge one step further? If so, it is a good proposal. But these tactics do not allow for the unexpected, for the anomalous, for something that requires a radical modification of the existing paradigm.

I recall a story told by Subrahmanyan Chandrasekhar, the Nobel prizewinning astrophysicist. During a press conference in the 1930s, about the proposal to build the 200-inch telescope on the Palomar Mountain, Edwin Hubble and Arthur Stanley Eddington were asked what they expected to find with the new telescope. Their reply was: "If we knew the answer, there would be no purpose in building it."

Indeed, astronomy has advanced when- ever the unexpected occurred, when a paradigm held sacrosanct by the majority of astronomers was shaken up. Such shifts occurred when it was realized that the Solar System is not at the centre of the Milky Way Galaxy, and again when it turned out that a good many nebulae are not part of our Galaxy but are galaxies in their own right lying far beyond the Milky Way. These paradigm shifts were not easy to achieve. Fritz Zwicky's ideas in the 1930s that clusters of galaxies may contain a lot of dark matter, or that the clusters may serve as gravitational lenses, were largely ignored at the time and we had to wait four decades to see them gain acceptance. Quasars and pulsars were both unexpected and anomalous in terms of the astrophysics of the time.

Closer examination of apparent anomalies can either show them to arise from artefacts, whereupon they cease to be important, and thus strengthen the existing paradigm, or the anomaly may force a change or modification of the paradigm. Either way, resolving the problem helps to develop the subject. Today, with large funds at stake, new facilities are proposed, designed and used with such a focused outlook that there is the danger of anything 'out of the way' being completely missed. Unlike Hubble and Eddington, today's proposers for a new facility begin by stating clearly what they expect to find with it.

Where does that leave the unexpected? Could the funding agencies and powersthat-be not reserve, say, ten per cent of their resources for venture ideas, for investigations of anomalies, for exploring alternatives to the existing paradigms? Provided, of course, that their originators have wellestablished credentials. Otherwise, science will be forced further away from what was once a free and open enquiry into the unknown, towards an exercise limited to confirming what is known. Jayant V. Narlikar is at the InterUniversity Centre for Astronomy and Astrophysics, Ganeshkhind, Pune 411007 India. 